\title{
GLOBALIZAÇÃO E TRANSNORMATIVIDADE: OS BENEFÍCIOS DOS DOCUMENTOS INTERNACIONAIS EM PROL DAS CIDADES
}

\section{GLOBALIZATION AND TRANSNORMATIVITY: THE BENEFITS OF INTERNATIONAL DOCUMENTS IN FAVOR OF CITIES}

\section{Elenise Felzke Schonardie ${ }^{1}$ Ana Maria Foguesatto ${ }^{2}$}

\section{RESUMO}

O artigo propõe a análise do processo de globalização e seus impactos no ambiente urbano, sob o viés da transnormatividade, com base no Protocolo Adicional à Convenção Americana sobre Direitos Humanos - Pacto de San Salvador e, ONU Habitat III e a Agenda 2030. O foco da apreciação centra-se no direito que toda pessoa tem de viver em meio ambiente sadio e a contar com os serviços públicos básicos nos termos do artigo 11 do Pacto e, sua combinação com os Objetivos para o Desenvolvimento Sustentável - ODS da Agenda 2030, em especial, o objetivo no 11 que visa tornar as cidades e os assentamentos humanos inclusivos, seguros, resilientes e sustentáveis. O método de abordagem utilizado foi o hipotético-dedutivo, por meio do procedimento bibliográfico, com coleta de dados indiretos e interpretação sociológica. Trabalha-se as noções da cidade na sociedade globalizada e a funcionalidade transnormativa em prol da concretização das cidades como espaços inclusivos, seguros, resilientes e sustentáveis. Conclui-se que os efeitos negativos do processo da globalização econômica são, entre outros, o

\footnotetext{
${ }^{1}$ Doutora em Ciências Sociais pela Universidade do Vale do Rio dos Sinos - UNISINOS; Mestre em Direito pela Universidade de Santa Cruz do Sul - UNISC; Graduada em Direito pela UNIJUI; Professora do Programa de Pós-Graduação Stricto Sensu em Direito - Curso de Doutorado e Mestrado em Direitos Humanos da Universidade Regional do Noroeste do Estado do Rio Grande do Sul - UNIJUÍ, vinculada a linha de pesquisa "Democracia, Direitos Humanos e Desenvolvimento"; Professora do Curso de Graduação em Direito da UNIJUÍ; Rio Grande do Sul - Brasil. Advogada. ORCID Id: https://orcid.org/0000-0002-9240-5886 Lattes: http://lattes.cnpq.br/0918929438055294 E-mail: elenise.schonardie@unijui.edu.br

${ }^{2}$ Mestre em Direito pela UNIJUÍ, foi bolsista CAPES; pesquisadora voluntária do Grupo de Pesquisa Direitos Humanos, Justiça Social e Sustentabilidade; bacharela em Direito pela UNIJUÍ; professora de Direito Empresarial da Faculdade América Latina - ljuí, RS - Brasil. Lattes: http://lattes.cnpq.br/8326506387572525 ORCID: https://orcid.org/0000-0003-0026-2943 E-mail: anafoguesatto@hotmail.com
} 
aumento das desigualdades sociais, da pobreza e da mercantilização dos espaços urbanos, bem como, a potencialização de riscos como a circulação de agentes patogênicos em escala global. Desse modo, remata-se por afirmar o protagonismos das cidades e a importância dos documentos internacionais de direitos humanos para a melhoria das condições de vida das pessoas nos centros urbanos.

PALAVRAS-CHAVE: Agenda 2030; Cidade; Direitos humanos; Globalização; Transnormatividade.

\section{ABSTRACT}

The article proposes an analysis of the globalization process and its impacts on the urban environment, from the perspective of transnormativity, based on the Additional Protocol to the American Convention on Human Rights - Pact of San Salvador and, UN Habitat III and the 2030 Agenda. It focuses in the appreciation of every person's right to live in a healthy environment and to count on basic public services in the terms of article 11 of the Pact. This is combined with the objective n. 11 of the 2030 Agenda for Sustainable Development, that vies for making cities and human settlements inclusive, safe, resilient and sustainable. The method of approach is the hypothetical-deductive through bibliographic procedure, with indirect data collection and sociological interpretation. It works on notions of city in globalized society and the functionality of transnormativity in the process of making cities that are consistent with the principles exposed by the legal documents. It is concluded that the negative effects of the process of economic globalization are, among others, the increase in social inequalities, poverty and the commercialization of urban spaces, as well as the potentialization of risks such as the circulation of pathogens on a global scale. In this way, it concludes by affirming the protagonism of cities and the importance of international human rights documents for improving the living conditions of people in urban centers.

KEYWORDS: 2030 Agenda; City; Human rights; Globalization; Transnormativity.

\section{Introdução}

As possibilidades de intensa mobilidade de pessoas, objetos e capitais pelo mundo é uma realidade marcante do fenômeno da globalização. Assim, faz-se necessário considerar não 
apenas a possibilidade, mas a efetiva contribuição que os documentos internacionais podem trazer a proteção dos direitos humanos. Portanto, o presente articulado apresenta uma análise das determinações do Protocolo Adicional à Convenção Americana sobre Direitos Humanos em Matéria de Direitos Econômicos, Sociais e Culturais (Protocolo de San Salvador) e as recomendações da ONU Habitat - Agenda 2030, no que se refere a proteção dos direitos humanos, no meio urbano, a fim de identificar e reduzir os efeitos negativos do processo de globalização e suas externalidades sobre as mesmas.

Desse modo, objetiva-se, primeiramente, analisar as implicações da nova ordem mundial, da sociedade globalizada e, num segundo momento a transnormatividade e sua importância para o debate e defesa dos direitos humanos, com destaque as normas e acordos internacionais de Direitos Humanos, no âmbito das cidades, referentes a melhoria da qualidade de vida das pessoas.

A relevância social do trabalho justifica-se na possibilidade de uma melhor compreensão do meio em que se vive, pois, a população localiza-se predominantemente nas cidades ${ }^{3}$. E, também, orientar a tomada de decisão por parte do poder público local para adoção de políticas públicas voltadas a melhoria da qualidade de vida da população no meio urbano em consonância com os documentos internacionais de proteção aos direitos humanos. O trabalho teórico é desenvolvido por meio do emprego do método de abordagem hipotético-dedutivo, com interpretação sociológica, aliado a técnica de pesquisa bibliográfica com a coleta de dados indiretos.

Inicia-se pela análise da globalização enquanto fenômeno determinante de uma nova ordem mundial, suas características, paradoxos e efeitos negativos em relação as cidades. A partir dos anos de 1990, a globalização, passa a ter uma maior interrelação entre os países nos campos social, político, econômico, cultural e do direito. Nesse sentido, trabalha-se as noções de cidade na atual sociedade global, bem como, a funcionalidade de transcender regras e normas entre os Estados-Nações, no sentido de buscar um melhor resultado para resolução de conflitos locais dos centros urbanos, nas sociedades ocidentais.

\footnotetext{
${ }^{3}$ Segundo os dados da Pesquisa Nacional por Amostra de Domicílios (PNAD) 2015 a maior parte da população brasileira, $84,72 \%$, vive em áreas urbanas. Ver mais em IBGE (2020). E, segundo a ONU, no ano 2019 mais de $55 \%$ da população mundial vive em áreas urbanas e a expectativa é de que esta proporção aumente para $70 \%$ até 2050 . Ver mais em Nações Unidas (2020). A organização tem promovido a discussão sobre "O papel das cidades na agenda global, incluindo cidades para o desenvolvimento sustentável, segurança alimentar, nutrição e mudança climática"; o que demonstra que as cidades, em especial as grandes aglomerações urbanas, passam a ser locais estratégicos para ações de promoção de melhoria da qualidade de vida da população.
} 
$\mathrm{Na}$ sequência, acercar-se à respeito dos documentos internacionais e suas determinações para a proteção dos direitos humanos e a melhoria das condições de vida nas cidades, observando-se as proposições da Agenda da ONU Habitat 2030, para redução das mazelas oriundas do processo de globalização, em especial da globalização de cunho econômico.

\section{Globalização e cidades}

O surgimento da globalização é apontado como sendo fenômeno antigo, que surgiu durante a desintegração de impérios e das antigas civilizações no período da Idade Moderna, porém essa versão não é unanimidade no mundo acadêmico. No entanto, não há dúvidas de que a globalização veio para assumir uma nova perspectiva para o mundo. A partir da segunda metade do século 20 , as sociedades ocidentais passaram a tomar forma de uma verdadeira sociedade global, onde as relações internacionais entre países contraíram relevante importância no espaço social e econômico local, perfazendo um vínculo de cooperação e interdependência entre os povos, bem como, intolerância e acentuação de conflitos locais, regionais e ambientais. Tais mudanças alicerçam a construção de uma nova ordem mundial.

Com o fim da Guerra Fria, a globalização capitalista começou a ganhar forma, para o sociólogo Octavio lanni (1999, p. 184): "nessa época ocorre uma transformação quantitativa e qualitativa do capitalismo, como modo de produção e processo civilizatório". Essas transformações trouxeram mudanças significativas na vida das pessoas, principalmente na área de processo de produção, na organização do trabalho.

Na medida em que se dá a globalização do capitalismo, como um modo de produção e processo civilizatório, desenvolve-se simultaneamente a sociedade global, uma espécie de sociedade civil global em que se constituem as condições e as possibilidades de contratos sociais, formas de cidadania e estruturas de poder de alcance global. Nessa mesma medida, desenvolvem-se as relações e os processos característicos da globalização, formam-se as estruturas do poder econômico e político também característicos da globalização. (IANNI, 1999, p. 205)

Os modernos ideais dos direitos humanos buscam defender os indivíduos perante o Estado, ou seja, dos excessos coercitivos do poder estatal. Esses ideais que construíram os princípios políticos e jurídicos, visando à consolidação de um conjunto de direitos fundamentais, que visam proteger a dignidade da pessoa humana. 
Analisa-se como a sociedade está organizada no tempo e no espaço, para assim poder entender melhor o processo de globalização ${ }^{4}$. Para Anthony Giddens (1991, p. 69): “A modernidade é inerentemente globalizante", ou seja, a globalização trouxe a modernidade, destaca-se assim, os níveis de distanciamento tempo-espaço para relações econômicas entre as diferentes formas sociais, culturais, políticas e econômicas, tornam-se longas. "A globalização pode assim ser definida como a intensificação das relações sociais em escala mundial, que ligam localidades distantes de tal maneira que acontecimentos locais são modelados por eventos ocorrendo a muitas milhas de distância e vice-versa". (GIDDENS, 1991, p. 69).

Ao direcionar o pensamento para âmbito local, vem as cidades com a imagem imediata de seu ritmo acelerado, sua concentração intensa de pessoas, aglomerado de casas e altos prédios, logo, tais fenômenos dão significado ao urbano. É possível captar a essência urbana nos fluxos de tempos e lugares, bem como, a hierarquização do espaço, no qual o urbano passa a sobrepor-se ao rural. E deste modo urbaniza-se "a sociedade como um todo" (ROLNIK, 1995, p. 12).

E, a cidade pode ser compreendida como uma espécie de ímã, o qual cria "um campo magnético que atrai, reúne e concentra os homens" (ROLNIK, 1995, p. 12). Destaca-se a importância do processo de sedentarismo e, também, o papel da religião para a organização da vida política urbana. "O templo era o ímã que reunia o grupo" (ROLNIK, 1995, p. 14). Assim, a religião e o sedentarismo contribuíram para a organização política e social, a normatização e a regulação interna do poder público.

Há uma relação intrínseca da cidade com a escrita, pois o surgimento da escrita e da cidade está ligado, a escrita foi um elemento essencial no processo de registrar a origem, as riquezas, os excedentes das cidades. "A cidade, enquanto local permanente de moradia e trabalho, se implanta quando a produção gera um excedente, uma quantidade de produtos para além das necessidades de consumo imediato" (ROLNIK, 1995, p. 16). Além da importância da escrita para o registro, aponta-se a própria cidade como sendo escrita, pois, através da arquitetura de cada cidade é possível "ler" suas histórias.

Raquel Rolnik (1995) entende a cidade enquanto Civitas, ou seja, cidade política. Nessa descrição refere-se de um caráter coletivo que emerge sobre a vida nas cidades, pois cidade

\footnotetext{
${ }^{4}$ Em relação a globalização há uma tendência teórica de demonstrar seus aspectos negativos (que não poucos), como o aumento das desigualdades sociais e econômicas, incremento da pobreza e outras mazelas. Mas a globalização enquanto fenômeno, também, proporcionou a globalização do local, a possibilidade de uma terminada cultura, atividade ou produto locais serem alçados a uma escala global; assim, como tem ocasionado o surgimento de novas sociabilidades e novos movimentos sociais. Ver mais em Sassen (2010).
} 
significa vida no coletivo. Deste modo, sinaliza-se para os consequentes sistemas de controle vindos da vida coletiva, como por exemplo, o controle dos fluxos. Da mesma forma, na cidade há a concentração da política administrativa a partir das relações de poder, sendo estas reforçadas pelo Estado e pelo estrato social dominante.

Quanto a ocupação sócio espacial, desde o surgimento das primeiras cidades, o lugar ocupado tem uma relação com o sagrado, com a divisão do trabalho, com o estrato ou posição social de cada indivíduo. Hodiernamente, questiona-se essa analogia a partir da Civitas Romana, acerca da centralidade do poder manter-se nas grandes metrópoles e se o papel político dos habitantes locais é levado em consideração, ou se existe apenas uma submissão entre esses, ressaltado a intensificação desse controle, pelas novas tecnologias. Contudo, esse mesmo espaço, também é palco de resistência de diversos movimentos populares (ROLNIK, 1995).

Em pleno século 21, as cidades são locais estratégicos para compreender as novas tendências que configuram a ordem social, Saskia Sassen (2010, p. 88): "Entre essas tendência, estão a globalização, o surgimento de novas tecnologias da informação, a intensificação das dinâmicas transnacionais e translocais e a presença e a voz fortalecida de tipos específicos de diversidade sociocultural". Porém, cada uma dessas novas tendências trazem uma carga de condições e consequências positivas e negativas para as pessoas que vivem nos centros urbanos. E, um novo modelo ou conceito de cidade surge como decorrência dessas intensificações de fluxos e dinâmicas transnacionais.

Neste novo modelo estão as cidades globais ${ }^{5}$, conhecidas como metrópoles mundiais com grandes aglomerações urbanas, que funcionam como centros de influência internacional, estão no topo da hierarquia urbana. Sassen (2010) introduziu o conceito de cidade global no início da década de 1990, com a publicação da obra The Global City. Para a autora, as cidades globais caracterizam-se pela "dispersão espacial das atividades econômicas nos níveis metropolitano, nacional e global que se associam à globalização e que contribuem para demanda de novas formas de centralização territorial das operações de controle e de

\footnotetext{
${ }^{5} \mathrm{O}$ presente trabalho não tem por objeto a defesa da cidade global, mas julga necessário sua abordagem em razão da sua posição privilegiada, ou seja, a cidade global como ponto nodal com capacidade para irradiar as novas determinações de poder, de modelo político, de intervenções econômicas, de alta tecnologia e de formas culturais diversas. As autoras, também, esclarecem que optaram por não abordar no presente trabalho a questão da "smart city", decorrente da revolução tecnológica e aludida como novo modelo de cidade para o século 21, por entenderem que o assunto referente as mesmas merece um trabalho específico. E, porque entendem que a revolução tecnológica que propiciou a criação das "Smart Cities" não está (e dificilmente estará) disponível à população negligenciada, marginalizada e excluída que vive nas cidades, em especial, nas grandes cidades e regiões metropolitanas (a revolução tecnológica encontra-se imbricada no fenômeno da globalização), para a qual os programas dos organismos internacionais procuram proporcionar serviços urbanos básicos.
} 
gerenciamento de alto nível" (2010, p. 90). Contudo, nem toda grande cidade alcança o status de cidade global, mas toda cidade global é um grande centro urbano, um local estratégico de onde emanam as principais determinações que rompem com a ordem política tradicional do Estado moderno, como se demonstrará na sequência.

As principais imagens que definem as cidades globais no contexto atual, merecem uma análise do ponto de vista sociológico, além de apenas dados e atributos. Com o estudo da sociologia urbana podemos enxergar que as consequências da globalização na nova ordem social, não se distinguem muito dos tempos antigos, isto porque, poder, mobilidade de capital, política, prob Olemas de moradia para a população de baixa renda, violência, descaso com o meio ambiente, sempre existiram em meio a sociedade, porém, nos dias de atuais possuem especificidades bem diferenciadas.

"Assim, os detalhes empíricos dessas formas sociais também são uma janela para apreender as características da atual fase da globalização". (SASSEN, 2010, p. 87). São dotadas de técnica e conhecimento em serviços de elevada influência nas decisões vinculadas à economia globalizada e aos avanços no progresso tecnológico, pois nessas cidades, há grande concentração e movimentação financeira, são dotadas de infraestrutura necessária para a realização de negócios nacionais e internacionais, além de contar com um sistema de telecomunicações de ponta.

Referencia-se as cidades globais como representação de espaço e tempo no urbano, a qual prioriza questões que envolvem economia local, a curto prazo para melhor integração dos fluxos. Destaca-se como uma característica das cidades globais a relativização de tempo e espaço, onde a facilidade de passar informações, em tempo real, para qualquer parte do mundo através de tecnologias avançadas, tornou-se de grande valia a sociedade atual. Cabe mencionar que nem sempre uma grande aglomeração urbana (metrópole ou megalópole) será considerada uma cidade global. Pois, existem cidades consideradas metrópoles e megacidades que não ocupam essa posição de cidade global.

As cidades globais possuem características que sustentam e compõem a sociedade, como a hipermobilidade, industrias de informação e comunicação global, bem como, a neutralidade do lugar e da distância, surgindo uma nova concepção cultural, por excelência é o espaço da concentração do poder. Neste cenário é que surge o desafio de recuperar o lugar da multiplicidade de presença na paisagem urbana, de forma a atingir toda a população de forma igualitária (SASSEN, 2010, p. 91). Destaca-se uma desconexão com o tempo natural das coisas, assim como, os ciclos diurnos e noturnos não param, ou seja, a cidade global não dorme. 
Pode ser considerada global a cidade que se configure como "nó" ou ponto nodal entre a economia nacional e o mercado mundial, congregando em seu território um grande número das principais empresas transnacionais; cujas atividades econômicas se concentram no setor de serviços especializados e de alta tecnologia, em detrimento das atividades industriais. Quando, por consequência, o mercado de trabalho fosse polarizado gerando novas desigualdades sociais e uma forma de segregação urbana dualizada (CARVALHO 2000, p. 72).

Numa perspectiva crítica, é possível afirmar que o conceito de cidade global vem sendo construído negando não só a especificidade histórica das metrópoles, mas a própria condição de ser metrópole das grandes cidades, o que aclara, a partir de um determinado momento, a substituição que tem sido feita atualmente de um termo pelo outro, quando se trata de discutir os problemas urbanos. "Mas negar as metrópoles em favor da cidade global é optar pela perspectiva sincrônica por oposição diacrônica, pela perspectiva que enfatiza as verticalidades por oposição as horizontalidades" (CARVALHO, 2000, p.75). Isso significa que a cidade global se define, exclusivamente, pela relação com a ordem global, deixando-se num segundo plano (inferior) a ordem local. As implicações dessa opção estão, diretamente, ligadas com a questão da segregação urbana que acompanha a definição do conceito de cidade global. (CARVALHO, 2000, p.75)

No que tange a fragmentação dos espaços sociais nas cidades globais, estas podem ser de fato, um modelo de sociedade segregada, pelas grandes diferenças nos estratos sociais, sendo nitidamente perceptível a desigualdade entre estes. Assim, surge a competitividade financeira, que potencializa essa segregação, não apenas pelas diferentes oportunidades de trabalho e educação, mas sim, pela valorização imobiliária decorrente de investimentos milionários, enquanto que, por menor, tem-se a revitalização dos espaços públicos, os quais integram apenas como marketing urbano, para embelezamento da cidade, com vistas a sustentabilidade.

Dentre as várias consequências trazidas pelo fenômeno da globalização, destaca-se, também, a transnormatividade ${ }^{6}$. A partir desse novo paradigma de sociedade globalizada e de cidades globais, pode-se analisar a relação jurídica entre Estados distintos, destacando-se as desigualdades sociais e socioambientais no âmbito das cidades. E, sobre essas questões ocupase o texto em sua sequência.

\footnotetext{
${ }^{6}$ A sociedade internacional contemporânea se caracteriza, cada vez mais, pela internacionalização de direitos, fato que não pode mais ser ignorado pelos Estados e indivíduos. (ver a obra "Ordem Global e Transnormatividade" de autoria de Wagner Menezes, publicada em 2005).
} 


\section{A transnormatividade a partir da sociedade globalizada: o Protocolo de San Salvador e a proteção dos direitos humanos nas cidades}

No atual contexto mundial intensificam-se a integração entre os estados, a fim de potencializar seu poder e controle sobre as instituições comerciais transnacionais e, os processos oriundos da globalização influenciam a unificação de algumas normas, por meio dos documentos e organismos internacionais. A globalização não abrange apenas a área do setor econômico (e financeiro), mas sim, possibilita que diversos setores (primário, secundário e terciário), de todo o mundo, avivem suas negociações e trocas com certa economia de tempo em seus pactos. Logo, pode-se afirmar que a globalização é uma espécie engrenagem que tornou possível a transnacionalização do direito.

Hoje, é possível realizar uma transcendência normativa, em benefício dos entes do setor público e privado, fazendo com que estes tenham pleno alcance de usufruir de normas que englobam ambos os poderes, de modo a possibilitar que empresas transnacionais possam abrir suas filias e operar em diversos países, concomitantemente.

A transnormatividade do direito é fruto da globalização, e seus efeitos fazem emergir a necessidade de uma consolidação entre os diferentes povos, governos, bem como, leva a repensar a ideia de uma dicotomia no ordenamento jurídico internacional. São entidades que se unem para trabalhar em prol de uma atmosfera amistosa, com certo equilíbrio, para que os países aliados consigam, cooperativamente, um melhor ambiente social de convivência e um setor econômico mais justo, com redução de desigualdades que ainda são bem presentes em âmbito nacional e internacional ${ }^{7}$.

Em âmbito global, no ao de 1966, formalizou-se o Pacto Internacional dos Direitos Econômicos, Sociais e Culturais, o qual foi ratificado pelo Brasil somente no ano de 1992. E, em âmbito regional, no ano de 1988, junto ao sistema interamericano de proteção dos direitos humanos, foi criado o Protocolo Adicional à Convenção Americana de Direitos Humanos em matéria de Direito Econômicos, Sociais e Culturais, conhecido como Protocolo de San Salvador e, ratificado pelo Brasil em 1996. Nesses documentos internacionais reconhecidos pelo Estado brasileiro, há disposições acerca do desenvolvimento progressivo, relacionados as questões econômicas, sociais e culturais que são pertinentes ao presente texto. A Convenção Americana de Direitos Humanos, conhecida como Pacto de San José da Costa Rica dá ênfase a cooperação

\footnotetext{
${ }^{7}$ Como a Organização das Nações Unidas - ONU, a Organização Mundial de Saúde - OMS, a Organização dos Estados Americanos - OEA, por exemplo.
} 
internacional entre os estados, para a progressiva efetividade dos direitos humanos, referindo em seu artigo 26 que:

Os Estados-partes comprometem-se a adotar providencias, tanto de âmbito interno, como mediante cooperação internacional, especialmente econômica e técnica, a fim de conseguir progressivamente a plena efetividade dos direitos que decorrem das normas econômicas, sociais e sobre educação, ciência e cultura, constantes na Carta da Organizações dos Estados Americanos, reformada pelo Protocolo de Buenos Aires, na medida dos recursos disponíveis, por via legislativa ou por meios apropriados. (PIOVESAN, 2000, p. 412).

O Protocolo Adicional à Convenção Americana sobre Direitos Humanos, (PROTOCOLO DE SAN SALVADOR, 2018), faz referência a necessidade dos estados membros em adotar medidas de busquem a proteção ao ambiente, como forma de garantir a efetivação dos direitos humanos, como por exemplo o texto do artigo 11 "Direito a um meio ambiente sadio: 1.Toda pessoa tem direito a viver em meio ambiente sadio ea contar com os serviços públicos básicos;

2. Os Estados Partes promoverão a proteção, preservação e melhoramento do meio ambiente."

Dessa forma, pode-se afirmar que Estado brasileiro, no uso de seus poderes, observou o conteúdo dos documentos internacionais, e assim, definiu no artigo 10 da Constituição da República Federativa do Brasil de 1988 os fundamentos e princípios do Estado Democrático de Direitos, bem como, os elementos que constituem a dignidade da pessoa humana, ressaltando a importância da política urbana (art. $182^{8}$ ) e os cuidados com o meio ambiente (art. $225^{9}$ ) para fins de cumprir o prescrito nos documentos internacionais e na própria Constituição Federal.

O não atendimento a essas disposições constitucionais, que têm conteúdo de direitos humanos, acaba por desencadear um processo de violação a estes direitos, tendo dentre as suas manifestações materiais, a acentuação da degradação ambiental e o aumento da situação de pobreza da população mais vulnerável. Destacando-se os estratos sociais menos favorecidos, ou seja, as comunidades mais carentes sem potencial de crescimento, em que a falta de recursos econômicos, sociais e culturais destas, acabam abrangendo o meio ambiente por meio de sua degradação, afetando, por exemplo, a saúde e a dignidade humana desses indivíduos. Logo, nos espaços em que a pobreza predomina, torna-se muito difícil manter uma boa qualidade de vida.

\footnotetext{
8 "Art. 182. A política de desenvolvimento urbano, executada pelo poder público municipal, conforme diretrizes gerais fixadas em lei, tem por objetivo ordenar o pleno desenvolvimento das funções sociais da cidade e garantir o bem-estar de seus habitantes. " (BRASIL, 2019)

${ }^{9}$ Conforme caput do artigo 225 da Constituição Federal de 1988 "Todos tem direito a um meio ecologicamente equilibrado, [...] essencial à sadia qualidade de vida [...]". (BRASIL, 2019)
} 
Esse quadro de violação de direitos, conduz à injustiça ambiental, isso porque, a noção de justiça ambiental se caracteriza pela negação de direitos básicos que sujeitam parcela considerável da população econômica e socialmente vulnerável à sofrerem as consequências negativas do desequilíbrio ambiental do meio no qual vivem.

No Brasil, em pleno século 21 pode-se afirmar que as injustiças sociais naturalizaram-se e, como elas, a exposição desigual à poluição e, o ônus desigual, com os custos para promover o desenvolvimento econômico e social, passam desapercebidos, praticamente invisíveis aos olhos dos brasileiros (em especial dos brasileiros que integram os estratos sociais mais elevados). Desse modo, pode-se trazer como exemplo de injustiça ambiental no meio urbano, os locais da cidade ocupados por indústrias, que no seu entorno, de um modo geral, tem os bairros de operários, formados à margem do regular parcelamento do solo urbano e, consequentemente, sem os devidos instrumentos urbanos básicos. Além é claro, da exposição dos moradores desses espaços a elevados níveis de poluição e negligenciados pelo poder público local. Outro exemplo, refere-se as ocupações irregulares de áreas urbanas para fins de moradia, muitas vezes em áreas de risco ambiental. E, mais, pode-se também listar a exposição à nova ameaça mundial, o Covid-19 ${ }^{10}$, que essa população em situação de vulnerabilidade, alocada nas regiões periféricas das cidades, em especial dos grandes centros urbanos, está sujeita.

Definitivamente, a pandeia da Covid-19, declarada pela Organização Mundial da Saúde - OMS, pôs termo a quaisquer dúvidas sobre a existência, concretude e potencialidades (no caso negativas) da globalização, enquanto fenômeno mundial. E, neste contexto de pandemia, as cidades passam a ter seu protagonismo realçado, pois as autoridades locais precisam agir com rapidez e em consonância as orientações (documentos) dos organismos internacionais, como a OMS. Neste aspecto, a transnormatividade acaba por exercer um papel fundamental para a acomodação e redução das externalidades trazidas por um problema que não é apenas local, mas que acaba por comprometer o local e, exigir medidas de salvaguarda para toda a população, em especial, a que está mais susceptível as carências materiais de toda ordem.

Com isso, o desafio do século 21, está em descobrir formas de efetivação dos direitos humanos, no meio urbano, em um cenário de desenvolvimento desigual e injustiças sociais. A

\footnotetext{
${ }^{10}$ Doença causada pela coronavírus. A Organização Mundial da Saúde (OMS) declarou, em 30 de janeiro de 2020, que o surto da doença causada pelo novo corona vírus (COVID-19) constitui uma Emergência de Saúde Pública de Importância Internacional - o mais alto nível de alerta da Organização, conforme previsto no Regulamento Sanitário Internacional. Em 11 de março de 2020, a COVID-19 foi caracterizada pela OMS como uma pandemia. Mais informações disponíveis em: https://www.paho.org/bra/index.php?option=com_content\&view=article\&id=6101:covid19\&ltemid=87 5
} 
busca por respostas que possam contribuir para a transformação desse quadro de desigualdade social e injustiças socioambientais em âmbito urbano, tem sido pauta de muitas investigações.

Cumpre ressaltar que os Estados Partes do Protocolo Adicional à Convenção Americana de Direitos Humanos devem comprometer-se com a adoção de medidas de ordem interna, por meio da cooperação entre os Estados, especialmente no setor econômico e técnico, levando em conta o grau de desenvolvimento de cada espaço, com o objetivo de alcançar progressivamente de acordo com a legislação interna, a plena efetividade dos direitos reconhecidos pelo Protocolo. E, nos últimos tempos houve uma intensificação da cooperação técnica e financeira, seja dos organismos transnacionais em relação aos diferentes estados-nação, seja em relação destes com os demais estados-nações, com repercussões no âmbito territorial interno desses estados, com o protagonismo para as cidades ${ }^{11}$.

Nesse sentido, há a possibilidade de adoção de algumas das ideias propostas pela Agenda 2030 da ONU para o desenvolvimento sustentável e, pela ONU Habitat III, no que se refere ao planejamento e desenho urbano local, por meio da revisão ou criação de leis locais que instituem o planejamento urbano, a regularização dos assentamentos precários/informais, o fornecimento de serviços básicos urbanos (água, saneamento, energia, mobilidade urbana e resíduos), o desenvolvimento econômico local (a partir da característica local) e o incentivo à participação cidadã, com o escopo de auxiliar o Poder Público local, na melhoria da qualidade de vida urbana.

\section{As proposições da ONU Habitat III e a Agenda 2030}

ONU Habitat é um programa social das Nações Unidas para os Assentamentos Humanos, que teve início em 1978 e, sede na cidade de Nairóbi, capital do Quênia. Esse programa trabalha com temas relacionados à vida nas cidades, bem como, com todos os atores sociais, como governos nas esferas federal, estadual e municipal, universidades, demais instituições privadas e até movimentos sociais. O foco central está na urbanização sustentável e nos assentamentos humanos. Como objetivo de desenvolver as áreas urbanas nos setores social, econômico e ambiental, para assim, proporcionar moradia adequada para os todos habitantes, possibilitando uma melhor qualidade de vida aos citadinos.

\footnotetext{
${ }^{11}$ Tal protagonismo das cidades é comprovado pelas medidas administrativas e legais adotadas pelas autoridades políticas das cidades (os prefeitos municipais) para conter a circulação de pessoas, bens e objetos em época de pandemia; determinar a utilização de equipamentos de segurança pelos citadinos e medidas de distanciamento social ou quarentena obrigatórios.
} 
Foi na segunda Conferência das Nações Unidas (Habitat II), realizada no ano de 1996, em Istambul na Turquia, que ficou definida a área na qual a Agenda ONU Habitat atuaria. Nessa oportunidade, estabeleceu-se os objetivos da referida Agenda em relação a garantia de abrigo adequado para todos os indivíduos e desenvolver assentamentos humanos sob o viés sustentável em um mundo ora urbanizado. A terceira Conferências das Nações Unidas relativas ao programa (Habitat III) ocorreu na América Latina, na cidade de Quito, capital do Equador, no ano de 2016. (NAÇOES UNIDAS, 2018)

O foco desta terceira conferência do Programa ONU Habitat foi "Moradia e Desenvolvimento Urbano Sustentável". A finalidade do evento era debater acerca dos processos de urbanização e de desenvolvimento sustentável realizados ou não nos últimos vinte anos e, a partir de analises desse período, foi projetado uma "Nova Agenda Urbana". Assim, busca-se um acordo entre os Estados-membros da Organização das Nações Unidas (ONU), para que a Nova Agenda Urbana seja implementada a nível global pelos países integrantes.

A ONU Habitat III resultou na "Declaração de Quito Sobre Cidades Sustentáveis e Assentamentos Urbanos para Todos" que deve ser entendida como uma extensão da Agenda 2030 para o Desenvolvimento Sustentável, que é um plano de ação definido em setembro de 2015, pelo encontro de líderes mundiais na sede da ONU em Nova York, para erradicar a pobreza, proteger o planeta e garantir que as pessoas alcancem a paz e a prosperidade. Agenda 2030 descreve em seu plano de ação os 17 objetivos que tratam das questões ambientais gerais e urbanas; tais objetivos são denominados e reconhecidos como ODS - Objetivos para o Desenvolvimento Sustentável.

1. Acabar com a pobreza em todas as suas formas ao redor do mundo;

2. Acabar com a fome, alcançar a segurança alimentar e melhorar a nutrição e promover a agricultura sustentável;

3. Garantir uma vida saudável e promover o bem-estar para todos em todas as idades;

4. Garantir uma educação inclusiva, equitativa e de qualidade e promover oportunidades de aprendizagem ao longo da vida para todos;

5. Alcançar a igualdade de gênero e capacitar todas as mulheres e meninas;

6. Garantir a disponibilidade de água e sua gestão sustentável e saneamento para todos;

7. Garantir o acesso a energia acessível, segura, sustentável e moderna para todos;

8. Promover um crescimento econômico sustentado, inclusivo e sustentável, emprego pleno e produtivo e trabalho decente para todos; 9. Construir uma infraestrutura resiliente, promover a industrialização inclusiva e sustentável e promover a inovação;

10. Reduzir a desigualdade nos e entre os países; 
11. Tornar as cidades e os assentamentos humanos inclusivos, seguros, resilientes e sustentáveis;

12. Garantir padrões sustentáveis de consumo e produção;

13. Adoptar medidas urgentes para combater as alterações climáticas e os seus efeitos;

14. Conservar e utilizar de forma sustentável os oceanos, mares e recursos marinhos para o desenvolvimento sustentável;

15. Proteger, restaurar e promover o uso sustentável dos ecossistemas terrestres, gerir as florestas de forma sustentável, combater a desertificação, travar e reverter a degradação do solo e reduzir a perda da diversidade biológica;

16. Promover sociedades pacíficas e inclusivas para o desenvolvimento sustentável, facilitar o acesso à justiça para todos e criar instituições eficazes, responsáveis e inclusivas em todos os níveis;

17. Fortalecer os meios de execução e revitalizar a Parceria Global para o Desenvolvimento Sustentável. (GAETE, 2018, s./p) (grifo nosso)

Esses 17 objetivos englobam questões relevantes a nível de interesse nacional e internacional pelos Estados-Membros da ONU, destacando-se nos mais diversos setores, como na economia, local à global, para obtenção de um meio ambiente saudável e de qualidade, com ênfase para as alterações climáticas, considera-se os impactos locais decorrentes da mudança do clima, nas áreas sociais e culturais, entre outras questões gerais. Essa Agenda 2030, vem renovar os objetivos de Desenvolvimento do Milênio, que foram promulgados em 2000 pela ONU. (PNUD, 2018)

A referida Agenda 2030 traz em seu objetivo de no 11 "Tornar as cidades e os assentamentos humanos inclusivos, seguros, resilientes e sustentáveis". Isso significa que, as cidades e/ou comunidades visando atingir a sustentabilidade local, devem ter como meta garantir o acesso à habitação digna, adequada e com preço acessível para todos, bem como, estender os equipamentos e serviços urbanos básicos para as comunidades e demais assentamentos que foram se formando sem quaisquer planejamento e segurança.

Contudo, a problemática de muitas cidades brasileiras está no grande número de pessoas que vivem em assentamentos irregulares e precários, lugares sem saneamento básico e água potável, inadequados e caracterizados pelo risco ambiental e pela complicada acessibilidade ao local. São espaços físicos considerados irregulares e informais, por não atenderem as formalidades legais relativas ao parcelamento e edificação do solo urbano, segunda a legislação local (municipa ${ }^{12}$ ). Dessa forma, os programas editados pelo ONU Habitat

\footnotetext{
${ }^{12}$ Segundo o artigo 30, inciso VIII, da Constituição Federal brasileira, compete aos municípios ordenar a ocupação do solo urbano, "[...] promover, no que couber, adequado ordenamento territorial, mediante planejamento e controle do uso, do parcelamento e da ocupação do solo urbano;" (BRASIL, 2019).
} 
III, mais o objetivo 11 (ODS) da Agenda 2030, vem reforçar a previsão do artigo 11 do Protocolo de San Salvador, para que as cidades sejam, efetivamente, espaços limpos (saudáveis), verdes e inclusivos, ou seja, com qualidade ambiental necessária para o desenvolvimento da vida humana, de forma progressiva, sustentável e acessível a todos os seus moradores.

Os documentos internacionais de proteção aos direitos humanos contam com o programa da ONU-Habitat e as ações da Agenda 2030, para a efetivação de direitos visando a sustentabilidade nos espaços urbanos e o desenvolvimento de uma vida digna para os habitantes das cidades. De um modo geral, a Agenda 2030, propõe ações para construir, gerenciar e viver melhor nas cidades, é um plano voltado para prosperidade das populações urbanas, para inclusão social e redução da segregação espacial, para saúde do planeta, com a intenção de "não deixar ninguém para trás". Pois afinal, todos têm o direito de viver em um ambiente que ofereça as condições básicas indispensáveis para uma vida digna. E, a adoção desses planos de ação propostos por agências transnacionais são de grande importância para a grande maioria das cidades brasileiras, pois poucas cidades teriam condições técnicas e viabilidade econômicas para, sequer, contratar estudos para elaboração desses programas. Por mais que inúmeras críticas surjam, no sentido de denunciar uma padronização em escala mundial promovida por tais programas; no presente, opta-se por destacar seus aspectos positivos de, literalmente, levar a luz, a água e o esgoto - saneamento básico, a espaços negligenciados pelo poder público local (bairros pobres, periféricos e favelas), diante da contínua e crescente desigualdade e pobreza manifesta em países em desenvolvimento, como é o caso do Brasil.

\section{Conclusão}

Conforme o demonstrado no início do texto o fenômeno da globalização alterou, significativamente, o modo de pensar, agir e interagir das sociedades ocidentais, trazendo consigo a relativização do tempo e dos espaços, bem como, aumentando a complexidade do mundo. E, como fenômeno, a globalização é social, econômica e cultural, uma forma impositiva de implantação de um modelo hegemônico. Pode-se apontar que os efeitos negativos do processo da globalização econômica são, entre outros, o aumento das desigualdades sociais, da pobreza e da mercantilização dos espaços urbanos de um modo geral, com exceção de locais privilegiados de cidades globais. Desse modo, os documentos internacionais de proteção dos direitos humanos, bem como os programas e ações elaborados pela comunidade internacional 
têm grande importância para a melhoria das condições de vida das populações, em especial, nos centros urbanos. Isto porque, os efeitos negativos do processo de globalização são objeto de preocupação e monitoramento da comunidade internacional, ensejando a elaboração e revisão de documentos que buscam atenuar, para as nações em desenvolvimento, os efeitos perversos desse processo, como por exemplo a negação do direito à terra urbana, à moradia, ao saneamento básico, à dignidade humana entre outros.

Nesse sentido, a transnormatividade tem se mostrado um importante instrumento para proteção e efetivação dos direitos humanos e, pode ser entendida como uma admirável maneira de garantir-se o elevado grau civilizacional alcançado pelas nações em prol daqueles que ainda não conseguem alcançar os benefícios da qualidade ambiental, dos avanços tecnológicos em favor vida humana digna para todos.

Em relação aos programas da ONU Habitat III e das ações propostas pela Agenda 2030, a adoção desses deve ser feita com cautela, levando-se em conta as características socioculturais locais, pois é tarefa altamente complexa tornar as cidades e os assentamentos humanos em espaços inclusivos, seguros, resilientes e sustentáveis, como propostos pela ONU. A possibilidade de implantação dos objetivos da Agenda 2030, em específico o objetivo 11 (que tem relação direta com o planejamento urbano, a regularização dos assentamentos precários/informais, o fornecimento de serviços básicos urbanos - água, saneamento, energia, mobilidade urbana e coleta de resíduos -, o desenvolvimento econômico local a partir das características locais e o incentivo à participação cidadã, com o escopo de auxiliar o Poder Público local, na melhoria da qualidade de vida urbana) é sim, uma forma de promoção e efetivação de direitos. Dessa maneira, as medidas trazidas ou sugeridas pelos documentos internacionais, como as propostas pela ONU Habitat III e pela Agenda 2030, podem contribuir para a criação ou recriação de espaços urbanos que favoreçam a cidadania e a melhoria da qualidade de vida e dignidade dos citadinos.

\section{REFERENCIAS}

BRASIL. Constituição da República Federativa do Brasil de 1988. Disponível em: <http://www.planalto.gov.br/ccivil_03/constituicao/constituicaocompilado.htm>. Acesso em 18 jun. 2019.

CARVALHO, Monica. Cidades Globais: anotações críticas sobre um conceito. In, SÃO PAULO EM PERSPECTIVA. Vol 14, n. 4, (out-dez), 2000 p. 70-82.

Disponível em: <http://www.scielo.br/pdf/spp/v14n4/9753.pdf>. 
GAETE, Constanza Martínez. Los 17 objetivos de la Agenda 2030 para el Desarrollo Sostenible adoptada por la ONU. 2015. Disponível em:

<http://www.plataformaurbana.cl/archive/2015/09/28/los-17-objetivos-de-la-agenda-2030para-el-desarrollo-sostenible-adoptada-por-la-onu/>. Acesso em: 01 out. 2018

GIDDENS, Anthony. As consequências da modernidade. Tradução de Raul Fiker. São Paulo: UNESP,1991.

IANNI, Octavio. A era do globalismo. Rio de Janeiro: Civilização Brasileira, 1999.

IBGE. Pesquisa Nacional de Amostra por Domicílio 2015. Disponível em:

https://biblioteca.ibge.gov.br/visualizacao/livros/liv98887.pdf . Acesso em 5 mai. 2020.

NAÇÕES UNIDAS. ONU-Habitat: Programa das Nações Unidas para os Assentamentos Humanos. 2018. Disponível em:https://nacoesunidas.org/agencia/onuhabitat . Acesso em: 04 set. 2018.

NAÇOES UNIDAS. ONU prevê que cidades abriguem 70\% da população mundial até 2050. Disponível em: https://news.un.org/pt/story/2019/02/1660701. Acesso em: 05 mai. 2020.

PIOVESAN, Flávia. (2000), Direitos humanos e o direito constitucional internacional, São Paulo: Max Limond. 2014.

PNUD. Programa das Nações Unidas para o Desenvolvimento: Erradicar a extrema pobreza e a fome. Disponível em: <http://www.pnud.org.br/ODM1.aspx, [consultado em 14-7-2014> Acesso em: 04 Set. 2018

PROTOCOLO DE SAN SALVADOR. Protocolo Adicional à Convenção Americana sobre Direitos Humanos em matéria de direitos econômicos, sociais e culturais. 2018. Disponível em:<http://www.cidh.org/Basicos/Portugues/e.Protocolo_de_San_Salvador.htm $>$. Acesso em: 18 set. 2018.

ROLNIK, Raquel. O que é a cidade. São Paulo: Brasiliense, 1995.

SASSEN, Saskia. Sociologia da Globalização. Tradução de Ronaldo Cataldo Costa. Revisão Téc. de Guilherme G. de F. Xavier Sobrinho. Porto Alegre: Artmed, 2010.

Trabalho enviado em 24 de fevereiro de 2020

Aceito em 08 de maio de 2020 